\title{
WASTE TO WISDOM: UTILIZING FOREST RESIDUES FOR THE PRODUCTION OF BIOENERGY AND BIOBASED PRODUCTS
}

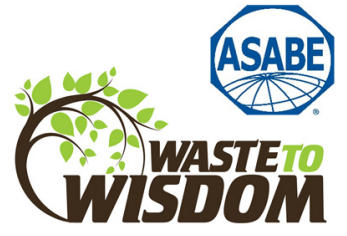

\author{
H.-S. Han, A. Jacobson, E. M. Bilek, J. Sessions
}

\begin{abstract}
The Waste to Wisdom project was part of the Biomass Research and Development Initiative (BRDI) and funded by the Department of Energy (DE-EE0006297) at an amount of \$5.8 million. Our interdisciplinary research team, consisting of academics, business professionals, and land managers, worked together for about four years (September 2013 to December 2017) to: 1) conduct field-based experiments to develop innovative tools and systems that improve the economics, accessibility, and production of quality feedstocks from forest residues, 2) develop and test stand-alone in-woods or near-theforest biomass conversion technologies (BCTs) for the production of biochar, torrefied wood, and briquettes, and 3) perform analyses to evaluate the economic feasibility of commercial deployment of BCTs and to quantify the life cycle economic and environmental benefits of utilizing forest residues with BCTs for the production of bioenergy and bioproducts. The research papers presented in this Special Issue cover key aspects of the research efforts and findings made by the project team. We encourage the audience to visit the project web site (http://wastetowisdom.com/) to learn more about the team's research on feedstock development, biomass conversion technologies, and the financial and environmental benefits of utilizing forest residues for production of bioenergy and biobased products.
\end{abstract}

Keywords. Air quality, Biomass conversion technology, Forest harvesting, Woody biomass.

$\mathrm{F}$ orest residues, including un-merchantable and small-diameter trees, tops, and limbs, produced during thinning and timber harvest operations, can be used to produce renewable bioenergy and bioproducts. The more efficient utilization of forest residues could also help offset the high costs of forest restoration activities, fire hazard treatments, post-harvest activities, and forest management in general. Forest residues have long been underutilized and treated as waste materials because of their high collection and transportation costs, as well as their low market value. While open burning is often employed to dispose of forest residues, this practice generally results in substantial negative economic and environmental impacts, including increased forest management costs and reduced local air quality.

At present, the greatest obstacle to more effectively utilize forest residues is high transportation cost. The integration of biomass conversion technologies (BCTs) with new

Submitted for review in January 2018 as manuscript number ES 12774; approved for publication as part of the Waste to Wisdom Collection by the Energy Systems Community of ASABE in January 2018.

Mention of company or trade names is for description only and does not imply endorsement by the USDA. The USDA is an equal opportunity provider and employer.

The authors are Han-Sup Han, Professor, Ecological Restoration Institute, Norther Arizona University, Flagstaff, Arizona; Arne Jacobson, Professor, Humboldt State University, Arcata, California; E.M. (Ted) Bilek, Economist, USDA Forest Service, Forest Products Laboratory, Madison, Wisconsin; and John Sessions, Professor, Oregon State University, Corvallis, Oregon. Corresponding author: Han-Sup Han, PO Box 15017, Northern Arizona University, Flagstaff, AZ 86011; phone: 928523-1049; e-mail: Han-Sup.Han@nau.edu. in-forest biomass operations could provide a cost-effective alternative to the long-distance transport of high moisture and low energy density forest residues. However, innovative new biomass feedstock technologies that produce high-quality feedstock materials from low-quality forest residues are needed to meet BCT feedstock specifications that include particle size and minimal contamination. BCTs can effectively convert comminuted forest residues into high-value fuels with desirable market characteristics (i.e., low moisture content and high energy density) and soil amendment products (i.e., biochar) in the woods, resulting in significantlyincreased transportation efficiencies. Using a process that is either in-woods or near-the-forests would also provide substantial environmental benefits by displacing fossil fuels, improving forest health, reducing catastrophic wildfires, and reducing greenhouse gas emissions.

The primary goal of the Waste to Wisdom project was to utilize waste forest residues to produce bioenergy and biobased products as a strategy to: 1) increase energy supply from renewable sources, 2) improve the environment, and 3 ) promote economic development in rural, forest-dependent communities in the western United States. Using forest residues as a feedstock for BCTs provides substantial social and economic benefits for rural, timber-dependent communities, including providing jobs for local workers and improving air quality through reduced emissions from open pile burns. In addition, converting forest residues into biochar is an effective strategy for carbon sequestration and improving the productivity of forest soils while reducing the incidence of catastrophic wildfires. 
This special issue of Applied Engineering in Agriculture includes 14 articles that are based on research and findings from the Waste to Wisdom project. Three of the articles cover topics related to feedstock collection and preparation, including coverage of moisture management for forest residues (Kizha and Han, 2018), moisture content of baled biomass (Dooley et al., 2018), and feedstock preparation using screening technologies (Woo and Han et al., 2018). Another four articles focus on technical issues related to mobile biomass conversion technology deployment, including articles on torrefaction system performance (Severy et al., 2018a), commercial biochar production technology (Severy et al., 2018b; Eggink et al., 2018), and electricity generation from a commercial biomass gasification system (Palmer et al., 2018). Also covered are topics related to the economics and logistics of biomass conversion (Berry and Sessions, 2018a, 2018b), economic demand curves for biomass products made from forest residues (Sasatani and Easton, 2018), and analysis of bio-product supply chains (Berry et al., 2018). The issue additionally includes articles related to the life cycle assessment of greenhouse gas and other emissions from biomass briquette production and use (Alanya-Rosenbaum et al., 2018), biochar utilization for mine site restoration (Page-Dumroese et al., 2018), and public acceptance of forest processes related to biomass conversion of residues (Sasatani et al., 2018). Together, these articles cover a wide range of forestry, technical, and social science topics relevant to the effective and efficient utilization of forest residues. A summary of key findings from the Waste to Wisdom project is covered in the sections that follow.

\section{Production of Quality Feedstock FROM FOREST RESIDUES}

During timber operations, treetops left from sawlog processing and small-diameter trees were delimbed and separated from the slash pile (Kizha and Han, 2016). There was an overall drop of moisture content in forest residues from $52 \%$ (freshly cut) to less than $20 \%$ over the 12 -month study period (Kizha et al. 2018). Processed treetops (i.e., stemwood only) were converted into different feedstock sizes using three mobile, high-production, comminution machines (chipper, micro-chipper and sawdust machine; Bisson and Han, 2016). The mean geometric lengths for processed treetops chipped using a regular chipper are highly uniform: more than $95 \%$ of the chipped materials were less than $50 \mathrm{~mm}$ in length. Micro-chipper and sawdust machines produced small sizes of chipped materials ( $<5 \mathrm{~mm}$ in length) to meet feedstock specification technologies that require small particles. All these chipping machines showed high production capacity levels (20-30 bone dry metric tons (bdmt)/hour), resulting in comminution costs ranging from $\$ 11$ to $\$ 13 / \mathrm{bdmt}$. The average bulk densities of chipped materials ranged between 220 and $322 \mathrm{~kg} / \mathrm{m}^{3}$, which is much higher than ground materials $\left(137 \mathrm{~kg} / \mathrm{m}^{3}\right)$. Further evidence of the good-quality feedstock produced from forest residues was the low moisture content $(<20 \%)$ and ash content $(<1 \%)$.

The Forest Concepts woody biomass baler (Auburn, Wash.) can handle all remaining forest residuals including low-density tops, branches, and understory brush biomass, and create high-density biomass bales that are amenable to truck transportation, long-term storage, and grinding at the time of use. A lightweight, modular baler was specified for mounting on forwarders, trailers, truck chassis and the like. A self-propelled, remotely-controlled baler was specified as an alternative to in-woods grinders. Finished bales had an average volume of $1.36 \mathrm{~m}^{3}$ and a typical bulk density of approximately $350 \mathrm{~kg} / \mathrm{m}^{3}$ at $15 \%$ to $29 \%$ moisture content (Dooley et al., 2018).

Appropriate biomass operations logistics coupled with the production of pre-processed feedstocks such as biochar, briquettes, or torrefied wood chips within a supply chain can enhance the economic transportation capacity of a biomass recovery operation. Transportable biomass conversion facilities producing biochar, briquettes, and torrefied wood were modeled and optimized for five sub-regions within the Pacific Northwest to characterize the potential economic viability of transportable designs. The optimal transportable design included facility movement on a 1- to 2.5 -year frequency depending on product and region with biochar being the most likely to be economically viable (Berry and Sessions, 2018). Biochar is the most likely candidate for a transportable conversion system given its relatively low power consumption, high allowable input moisture content, wider range in its acceptable feedstock size specifications, and low product transportation cost.

\section{FOREST RESIDUES CONVERSION INTO BIOBASED PRODUCTS}

All three biomass conversion technologies evaluated in this study were modified to be suitable for mobile, in-field operation with forest residues. By analyzing the quality of products from each machine with different feedstocks, specifications were developed based on moisture content, ash content, and particle size distribution of comminuted forest residues. The biochar machine could accept the widest range of feedstocks up to $100 \mathrm{~mm}$ particles sizes, $20 \%$ ash, and $25 \%$ moisture; briquettes with the highest density and durability were produced from feedstock between $8 \%$ and $12 \%$ moisture content and a high fraction $(>50 \%)$ of fine particles or sawdust; the torrefier performed best with feedstock moisture content below $10 \%$ but could accept up to $25 \%$; feedstock particle size specifications for the torrefier were stringent, requiring the majority of the particles to be between 3 and $25 \mathrm{~mm}$.

One of the main constraints across all technologies is achieving the target moisture content before conversion. This was successfully completed by integrating waste heat drying. Excess heat from torrefaction or biochar production can be recovered to dry incoming residues that can be sent to the original BCT or another on-site BCT. BCT plant electrical loads can be met using forest residues with a biomass gasifier generator set as an alternative to a diesel generator. A mobile biomass gasifier was able to provide electricity to unbalanced, highly variable BCT loads with low power factors.

Through the Waste to Wisdom project, the three main BCTs plus a gasifier generator and a waste heat dryer were tested individually and within integrated demonstration systems to collect operational performance data for economic and 
environmental analyses. Two demonstration systems resulting from this project are highlighted in figure 1 .

\section{ECONOMICS OF ForEST-TO-PRODUCT USING THREE Biomass Conversion PaThWAYS}

Forest-to-Product costs depend on feedstock costs to the transportable biomass conversion facility, product types to be processed, facility scale, BCT facility location on the landscape, and the frequency that the transportable facility is relocated. Three articles in the collection address the supply chain costs from roadside to market for the transportable facility. Berry and Sessions (2018a) develop a conceptual and mathematical strategic model to examine the forest-to-product supply chain for a transportable biomass conversion facility including economics of scale and the costs of facility relocation. Berry and Sessions (2018b) focus on the generation of a tactical-based landscape model to optimize biomass extraction, transportation, conversion and product production within a market system. Pathways include supply options at landings (burn, grind, chip, bale), centralized landings (grind/chip), biomass conversion facilities (biochar, briquettes, torrefied wood) and delivery to final market. Berry et al. (2018) apply the strategic model to five subregions in Washington, Oregon, and Califorina to examine how biomass availability, biomass characteristics, and state regulatory and energy cost structures affect supply chain costs for producing biochar, torrefied wood, and briquettes using the transportable biomass conversion concept.

The presence of a local pulpwood market can affect biomass availability and characteristics. State regulations and energy cost structures can also affect overall economics. Feedstock costs to the biomass conversion facility in five sub-regional studies in Washington, Oregon, and California varied from $\$ 30$ to $\$ 50 / \mathrm{bdmt}$ of feedstock including moving the transportable facility around the landscape. Producing the biomass products within the facility (the sum of CapEX, OpEX, Drying, Conversion and Packaging) was the mostcostly component (fig. 2) and scale dependent (figs. 3 and 4).

Regional feedstock composition and availability was the largest indicator of feedstock delivery costs. The absence of a regional pulp market provided low-cost small logs and logs of noncommercial species that could be handled by conventional self-loading log trucks and short trailers. Where local pulp markets exist, harvest residuals were primarily branches. Feedstock handling and transport were more expensive, requiring chipping, grinding, or baling at the landing or central landing before transport to the BCT. Transportation costs are important, but they are overshadowed by the cost of biomass conversion technologies examined in this research (fig. 2).

Biomass conversion costs are technology dependent and may be the key to lowering supply chain costs to enable market viability. Feedstock moisture management was important, particularly for those biomass conversion technologies that require low moisture feedstock. Active drying based on waste heat recovery can extend the operational season for the BCT equipment, thereby improving system economics. Although components of transportable plants are modular, sufficient economies of scale exist such that for the range of transportable plants evaluated (15,000 to $50,000 \mathrm{bdmt}$ annual input), larger transportable plants have lower conversion costs than smaller plants (figs. 3 and 4).

Results generally indicate that system costs are largely dependent on market pricing, plant assumptions, and conversion estimates. While processing and transportation costs are smaller, they are, nonetheless, important contributors for small-scale biomass conversion facility design configurations. Using the biomass conversion technologies examined in the Waste to Wisdom project, access to electrical grid-energy could be the difference between an economically-viable supply chain operation and one that is not.

Economics depends not only on supply, but also on market demand, which was covered by Sasatani and Eastin (2018). They developed models to estimate demand curves for Waste to Wisdom products including wood briquettes, torrefied briquettes, and biochar that would be placed into five selected local markets in the northwestern United States. The demand curves were then used to estimate maximum factory prices of wood products at these locations over a range of production levels. Markets were assumed to be smaller residential users.

Sasatani and Eastin (2018) found that when considering the location of a bioenergy production facility, distance to market is a critical factor. Locations closer to larger urban

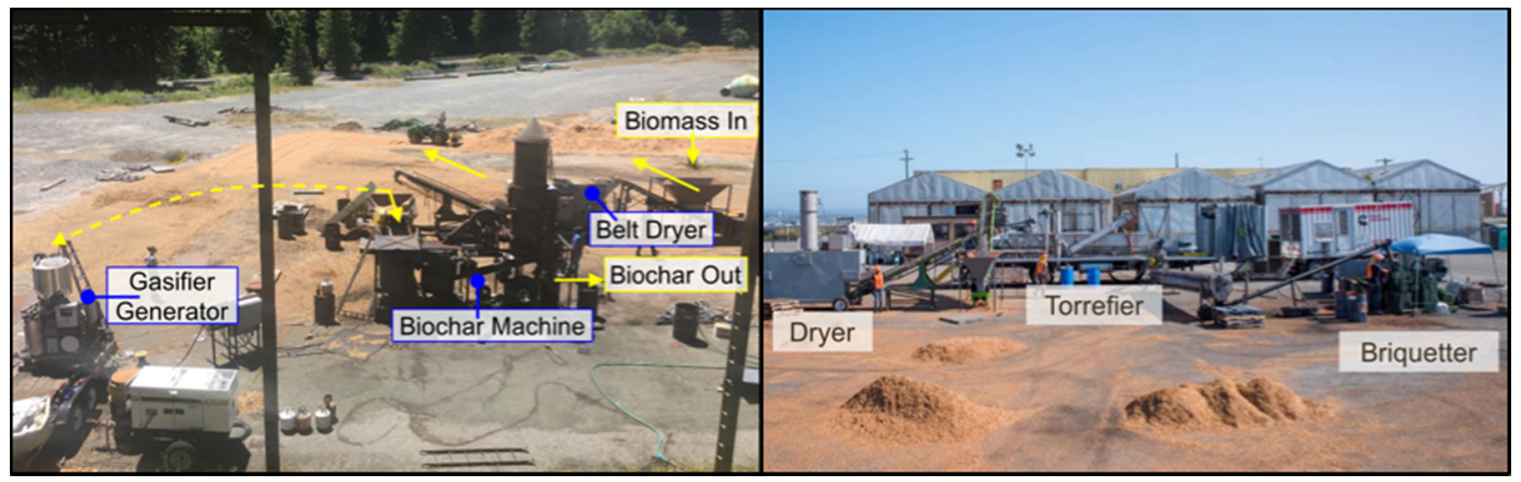

Figure 1. Integrated biochar system (left) using a waste heat dryer to dry forest residues before conversion and a biomass gasifier generator to provide electricity to the plant. The input rate was $320 \mathrm{~kg} / \mathrm{h}$ (dry basis) with $79 \mathrm{~kg} / \mathrm{h}$ of biochar production. Torrefied biomass briquettes were produced in a continuous flow torrefaction demonstration plant (right) using a dryer, torrefier, and briquetter in series. The input rate was $650 \mathrm{~kg} / \mathrm{h}$ with $550 \mathrm{~kg} / \mathrm{h}$ of torrefied briquette production. 


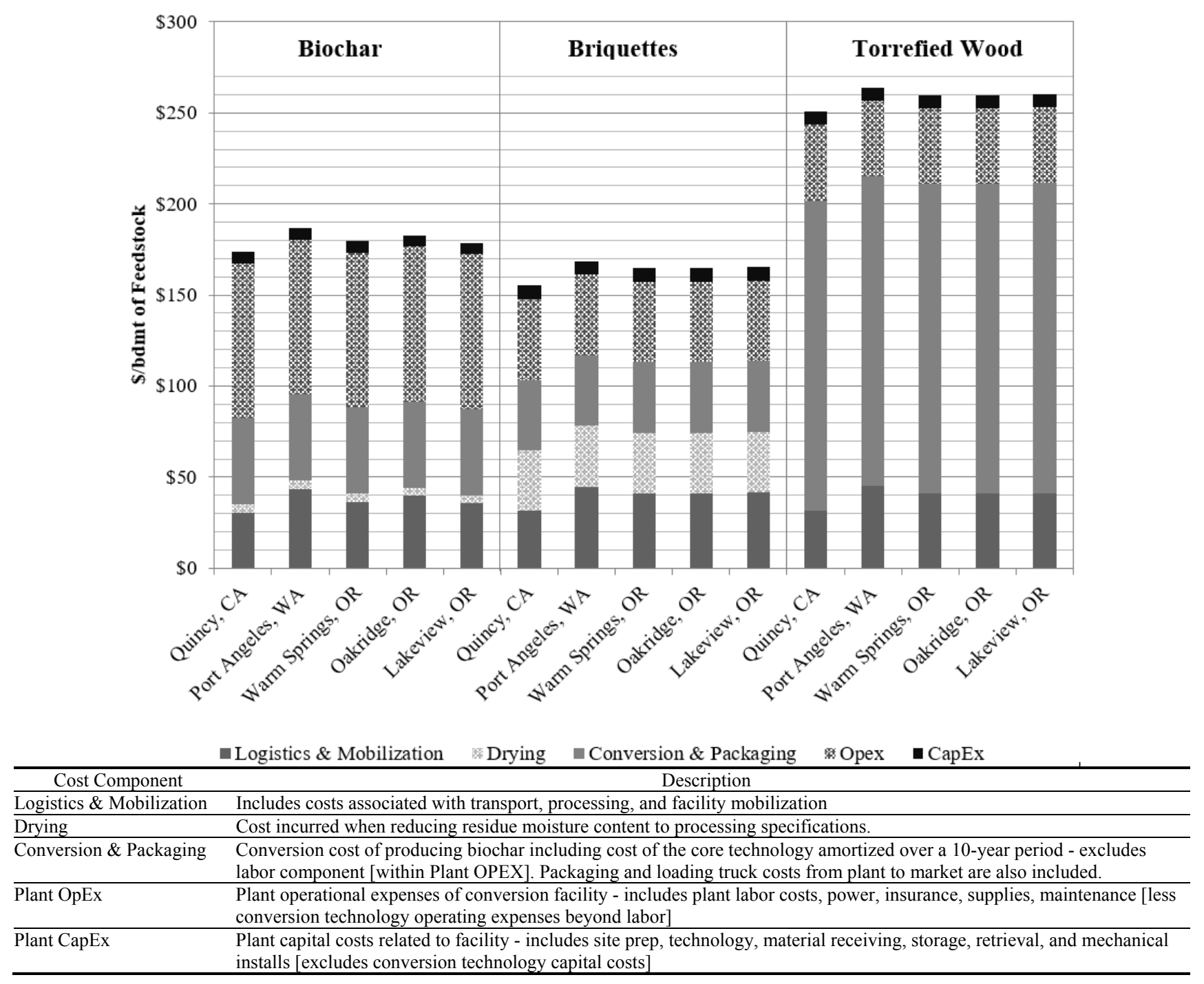

Figure 2. Production cost of product expressed as $\$ / b d m t$ of feedstock.

centers offered higher potential profits for smaller solid wood energy producers who would essentially be price takers. On the other hand, in the case of biochar, with smaller volumes of higher-margin product, the internet may help to overcome problems with market access.

Market prices will depend on consumer perceptions of the products and may also depend on product quality; but there are likely to be tradeoffs between quality and production cost. However, even high retail prices for these products may not guarantee profitability, especially in locations with market access issues and limited market potential due to smaller nearby populations. Producers in rural areas need to be aware of and sensitive to possible oversupply issues.

\section{Environmental Impacts and Public Perceptions}

The Waste to Wisdom concept may not be viable and will not be sustainable if there are not positive environmental impacts from it. Environmental impacts were examined from three different perspectives. Life cycle analyses (LCA) were conducted on the processes and on the products to determine the impacts on the carbon cycle. Air quality and human health impacts from inhalation of particulate matter from burning slash piles was also examined. And the impact of applying biochar, particularly on degraded mine sites was considered.

In their life cycle analysis work, Alanya-Rosenbaum et al. (2018) found that utilization of post-harvest residues as biofuel as opposed to the typical pile and burning practice shows a notable environmental advantage; notably that nearwoods bioenergy production systems using power from onsite wood gasifier showed better environmental performance than their fossil fuel alternatives: on-site diesel and in-town grid electricity. Residues that are gasified to produce electricity at a near-woods conversion site reduce greenhouse gas emissions by 2.4 times compared with hauling those residues four hours to a larger in-town biomass generation facility. An on-site diesel generator would have a total global warming impact about 2.8 times higher than the gasifier. In another example, LCA of biomass briquettes produced from biomass waste in substituting for propane in domestic heating reduced greenhouse gas emissions by $94 \%$. 


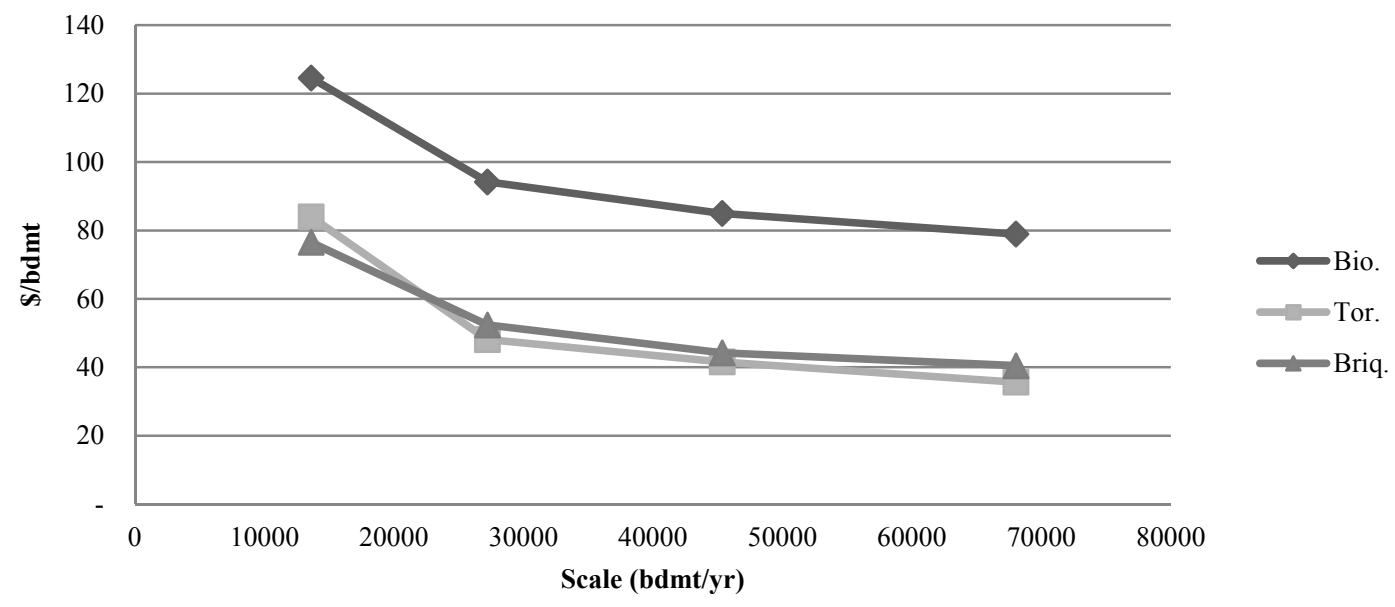

Figure 3. Core operational expenses [plant labor costs, power, insurance, supplies, maintenance, etc. (less conversion technology operating expenses beyond labor)] vs. plant scale (bdmt/yr). As plant scale increases, operational expenses (per unit input) decrease. Costs are expressed as \$/bdmt equivalent of feedstock.

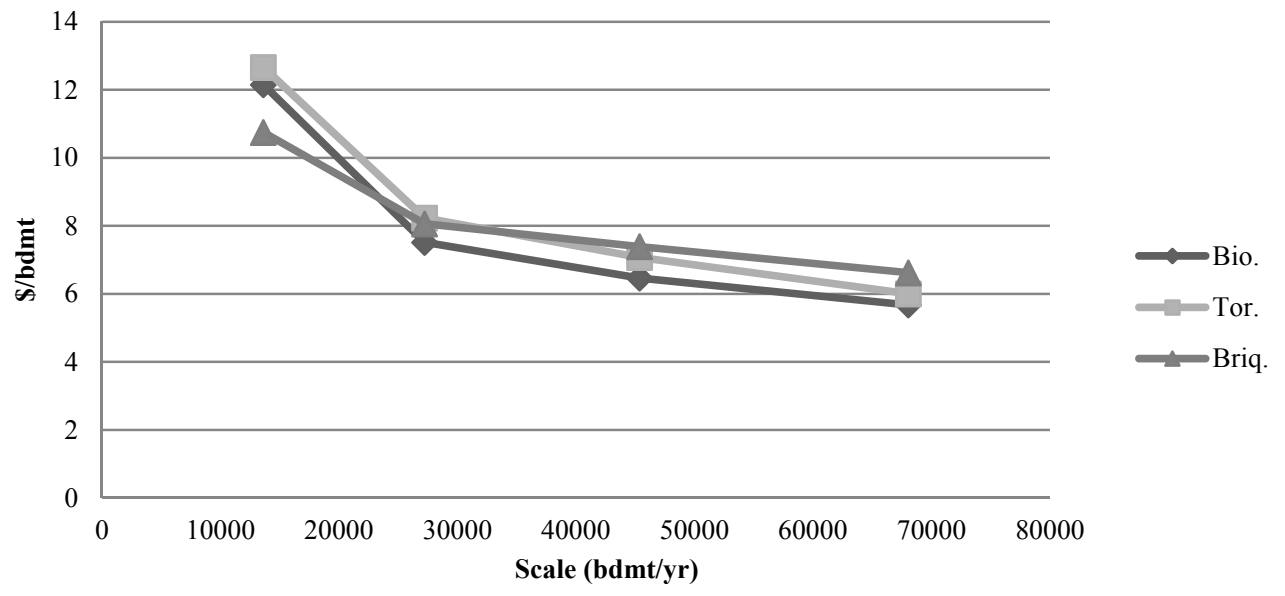

Figure 4. Core capital expenses [site prep, technology, MRS\&R (Material Receiving, Storage, and Retrieval at the BCT site), mechanical installs (less conversion technology capital costs)] vs. plant scale (bdmt/yr). As plant scale increases, capital expenses (per unit input) decrease. Ten-year facility service life. Costs are expressed as \$/bdmt equivalent of feedstock.

Human health impacts were also covered in Waste to Wisdom. Sifford et al. (2018) looked at the potential health consequences of pile burning by modeling slash piles, locations, and weather in Washington. They processed piling scenarios through a chemical transport modeling system and analyzed the results using geographic information system (GIS) methods. Particulate matter from burning slash piles can travel great distances away from the burns and have detrimental health effects on densely-populated urban areas as well as smaller rural communities. Sifford et al. (2018) found that human intake of particulate matter (PM) heavily depends on pile locations and weather. PM from burning a large pile in a given location can impact less than 100 people on one day or more than 200,000 people on a different day.

Sifford et al. (2018) suggest that methodologies developed in air quality modeling work could help policymakers to identify best practices in fire management based on sitespecific factors and pre-burn smoke modeling to make better decisions for burn dates. Alternatively, policies and actions such as utilization that would avoid in-forest pile burning would also reduce adverse human health impacts and poor air quality.

The effectiveness of biochar was studied with a focus on mine site remediation because abandoned mine sites are an issue on remote forest lands and offer a potentially highervalued use for biochar produced from nearby forest waste (Page-Dumroese et al., 2018). They found that biochar made from wood waste in Montana and Idaho can be applied relatively easily to mine sites, where it aids in the site reclamation by increasing site cover and speeding revegetation. Application rates of around $22 \mathrm{Mg} / \mathrm{ha}$ (9.8 tons/acre) are the most effective for changing soil physical, chemical, and biological properties.

The forest waste utilization conceived in Waste to Wisdom will not be possible if thinning operations and production of products from those thinnings are not also socially acceptable. Sasatani et al. (2018) evaluated social acceptance through a survey to determine public perceptions 
of forest waste utilization. While there is general public support for forest thinning and using those thinnings to produce products such as biochar and bioenergy, opposition to thinning generally increases along with increasing population density, suggesting different public education strategies and messages regarding the role of forest thinning in forest health depending on the population density.

\section{CONCLUSIONS}

Forest residues have long been underutilized and treated as waste materials because of their high collection and transportation costs as well as the low market value of forest residues. The Waste to Wisdom project was to improve the utilization of forest residues through the use of BCTs that operate at or near the forest. The lessons we learned from this project include operational logistics to produce quality feedstock from forest residues, technical specifications and capacity of BCTs, and socio-economic and environmental benefits from utilization of forest residues. The production of torrefied pellets and briquettes can strengthen energy sources by incorporating renewable fuels into current bioenergy and coal-fired energy facilities. In addition, converting forest residues into biochar is an effective strategy for carbon sequestration and improving the productivity of forest soils while reducing the incidence of catastrophic wildfires. The 14 articles presented in this Special Issue explain in detail the outcomes of the project in a number of key research topic areas, and we encourage the audience to visit the project web site (http://wastetowisdom.com/) to learn about the rest of the research outcomes, final reports, webinar presentations, and photo essays.

\section{ACKNOWLEDGEMENTS}

This material is based upon work supported by a grant from the U.S. Department of Energy under the Biomass Research and Development Initiative program: Award Number DE-EE0006297.

\section{REFERENCES}

Alanya-Rosenbaum, S., Bergman, R. D., Ganguly, I., \& Pierobon, F. (2018). A comparative life-cycle assessment of briquetting logging residues and lumber manufacturing coproducts in Western United States. Appl. Eng. Agric., 34(1), 11-24. https://doi.org/10.13031/aea.12378

Berry, M., \& Sessions, J. (2018a). The economics of biomass logistics and conversion facility mobility: An Oregon case study. Appl. Eng. Agric., 34(1), 57-72. https://doi.org/10.13031/aea.12383

Berry, M., \& Sessions, J. (2018b). A forest-to-product biomass supply chain in the Pacific Northwest, USA: A multi-product approach. Appl. Eng. Agric., 34(1), 109-123. https://doi.org/10.13031/aea.12384
Berry, M., Sessions, J., \& Zamora-Cristales, R. (2018). Subregional comparison for forest-to-product biomass supply chains on the Pacific West Coast, USA. Appl. Eng. Agric., 34(1), 157174. https://doi.org/10.13031/aea.12526

Bisson, J. A., \& Han, H.-S. (2016). Quality of feedstock produced from sorted forest residues. Am. J. Biomass Bioenergy, 5(2), 8197. https://doi.org/10.7726/ajbb.2016.1007

Dooley, J. H., Wamsley, M. J., \& Perry, J. M. (2018). Moisture content of baled forest and urban woody biomass during longterm open storage. Appl. Eng. Agric., 34(1), 223-228. https://doi.org/10.13031/aea.12281

Eggink, A., Palmer, K., Severy, M., Carter, D., \& Jacobson, A. (2018). Utilization of wet forest biomass as both the feedstock and electricity source for an integrated biochar production system. Appl. Eng. Agric., 34(1), 125-134. https://doi.org/10.13031/aea.12404

Kizha, A. R., \& Han, H.-S. (2016). Processing and sorting forest residues: Cost, productivity and managerial impacts. Biomass Bioenergy, 93, 97-106. https://doi.org/10.1016/j.biombioe.2016.06.021

Kizha, A.R., H.-S. Han, J. Paulson, and A. Koirala. 2018. Strategies for reducing moisture content in forest residues at the harvest site. Appl. Eng. Agric., 34(1), 25-33. https://doi.org/10.13031/aea.12427

Page-Dumroese, D. S., Ott, M. R., Strawn, D. G., \& Tirocke, J. M. (2018). Using organic amendments to restore soil physical and chemical properties of a mine site in northeastern Oregon, USA. Appl. Eng. Agric., 34(1), 43-55. https://doi.org/10.13031/aea.12399

Palmer, K. D., Severy, M. A., Chamberlin, C. E., Eggink, A. J., \& Jacobson, A. E. (2018). Performance analysis of a biomass gasifier genset at varying operating conditions. Appl. Eng. Agric., 34(1), 135-143. https://doi.org/10.13031/aea.12414

Sasatani, D., \& Eastin, I. (2018). Demand curve estimation of locally produced woody biomass products. Appl. Eng. Agric. 34(1), 145-155. https://doi.org/10.13031/aea.12392

Sasatani, D., Eastin, I. L., Bowers, C. T., \& Ganguly, I. (2018). Public acceptance of pre-commercial thinning and energy and soil amendment products from post-harvest residues in western forests of the U.S. Appl. Eng. Agric., 34(1), 99-108. https://doi.org/10.13031/aea.12366

Severy, M. A., Chamberlin, C. E., Eggink, A. J., \& Jacobson, A. E. (2018a). Demonstration of a pilot-scale plant for biomass torrefaction and briquetting. Appl. Eng. Agric., 34(1), 85-98. https://doi.org/10.13031/aea.12376

Severy, M. A., Carter, D. J., Palmer, K. D., Eggink, A. J., Chamberlin, C. E., \& Jacobson, A. E. (2018b). Performance and emissions control of commercial-scale biochar production unit. Appl. Eng. Agric., 34(1), 73-84. https://doi.org/10.13031/aea.12375

Sifford C., Pierobon F., Ganguly I., Eastin I., Alvorado E., and Rogers L. (2018), Developing an Impact Assessment of Local Air Quality as a Result of Biomass Burns. CINTRAFOR WP 128. University of Washington, Seattle, pp 65.

Woo, H., \& Han, H.-S. (2018). Performance of screening biomass feedstocks using star and deck screen machines. Appl. Eng. Agric., 34(1), 35-42. https://doi.org/10.13031/aea.12385 